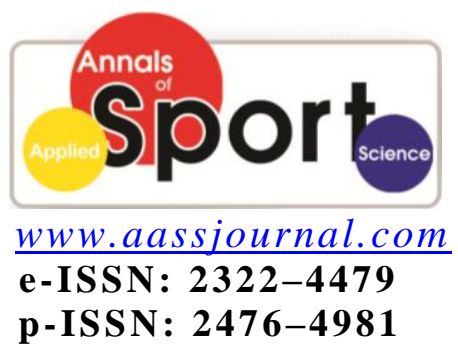

Driginad Article

Received: $28 / 11 / 2014$

Accepted: 11/07/2015

\title{
The Effects of Backpack Weight on the Static and Dynamic Balances of Female Students
}

\author{
Saeid Bahiraei*, Maryam Jafarian, Ebrahim MohammadAliNasab
}

- Department of Sport Injury and Corrective Exercise, Faculty of Sport Sciences, University of Guilan, Rasht, Iran.

\begin{abstract}
The main aim of this study was to investigate the effects of carrying backpack on the balance of female students aged 9-11 years. In the present study, 30 students (mean age of 15.02 \pm 2.07 years, height of $140 \pm 8 \mathrm{~cm}$, and weight of $41.51 \pm 15.26 \mathrm{~kg}$ and body mass index of $20.68 \pm 5.39 \mathrm{~kg} / \mathrm{m} 2$ ) were randomly selected. Their static and dynamic balances were evaluated using single-leg stance and $\mathrm{Y}$ tests in both cases of with and without a backpack. Based on the research findings, there was a significant difference $(\mathrm{P}=0.035)$ between the cases of with and without carrying a backpack (as much as $10 \%$ of body weight) in a static balance in girls aged 9-11 years. Also, a significant difference was found between the anterior direction $(\mathrm{P}=0.003)$ in the left leg and internal posterior $(\mathrm{P}=0.003)$ and external posterior $(\mathrm{P}=0.003)$ directions in the right leg in the dynamic balance, while no significant differences were seen in other directions in the two legs. Moreover, in the assessment of the effect of backpack on different directions using $\mathrm{Y}$ test, it was observed that backpack weight has the greatest effects on both legs in the internal posterior direction. The results of the current research showed that carrying a backpack weighing $10 \%$ of the body weight by female students aged 9-11 reduced static and dynamic balances. According to the results, it is suggested that school health officials and parents should apply effective planning and training for students on carrying backpack with suitable weight.
\end{abstract}

Key Words: Backpack, Static Balance, Y Balance Test.

Corresponding Author:

Saeid Bahiraei

E-mail: saeid_bahiraei86@yahoo.com 


\section{INTRODUCTION}

Reducing physical activity and using different tools and facilities in daily life are inevitable, which makes humans to be exposed to a variety of illnesses and body deformities. Thus, studying and proposing the necessary standards of equipments and assessing their effects on users' health are important. Backpack is a popular tool among different classes of the society, especially students, children and adolescents. In different researches, it has been reported that from among the various methods of carrying school supplies (such as a shoulder bag, briefcase, wheeled bag, front pack, etc.), backpack is more popular and prevalent (1-5). Students' non-standard postures when walking and carrying heavy backpacks on their way to school and vice versa have worried parents, teachers and the whole society, thus making researchers to investigate the adverse effects of carrying in appropriate backpacks. The burden of carrying heavy bags may be observed as musculoskeletal disorders and balance problems among students $(6,7)$, thus leading to a permanent postural deviation (8) as well as the lack of postural balance control (9). Teenagers' muscles, ligaments and bones are still in their developmental stages and physical grow this up to the end of puberty which is about the age of 19; they are highly sensitive between the ages of 6 and 14 years and prone to most possible injuries and trauma (10). Of the adverse effects, those caused by heavy backpacks which can induce kyphosis, scoliosis $(11,12)$ and forward head (13) were reported, and each of these abnormalities can cause balance disorders in students. Balance is an inseparable part of almost all the daily key activities for people's performance. Devroey et al. (2007) stated that balance is an important part of a person's ability which is involved in almost any form of activity (2). Balancing is a complex motor skill that describes a dynamic posture to prevent a fall (2). Several researches have studied the effects of carrying backpack in terms of physiological, mechanical and pathological aspects. This investigation, especially in recent years, has been focused on by experts in biomechanics $(2,8,9,14)$. Of the possible negative effects of carrying a heavy backpack, its impact on biomechanics of walking was reported $(2,4)$. On the other hand, balance is one of the important factors of motor fitness which is closely related to the efficiency of the neuromuscular system. However, there is lack of studies on changes of balance in female students following the use of backpack (15). In their study, Hong et al. (2003) observed that carrying heavy backpacks (more than 10\% of body weight) increased mechanical and physiological stresses. They suggested a backpack equivalent of $10 \%$ of body weight as a standard bag weight for 10-year-old students, showing that the proposed load causes the least disruption of the mechanical and metabolic processes and balance disorders (16). In a research, Negrini et al. (1999) observed that the average weight of school bags carried by the students of an Italian school for3 weeks was $9.5 \mathrm{~kg}$. The figure recorded was up to $16.3 \mathrm{~kg}$. They further observed that $34.8 \%$ of the students at the mentioned school carried bag with a relative weight of more than $30 \%$ of their body weights at least once a week and according to their results, the increase in the backpack weight leads to the enhancement of balance disorders, especially in the anterior-posterior direction (17). In a review work, Brackley and Stevenson (2004) evaluated the physiological, epidemiological and biomechanical records of carrying backpack in order to determine the optimum backpack weight for children. In their study, a comprehensive review on previous studies was performed to assess and propose an appropriate and approximate backpack weight to reduce postural disorders and 
determine the research aspects needed for future studies. The researchers stated that the physiological, epidemiological and biomechanical information support the recommended weight limits of 10 to $15 \%$ of body weight of a backpack. Yet, determination of the relationship between using a backpack and injuries, as well as assessment of factors such as backpack design, personal characteristics including physical fitness, and the effect of adaptations required when carrying a backpack require further research (18). Due to the increasing use of backpacks with excessive weights by students, importance of balance in maintaining their static and dynamic body postures to prevent injuries and musculoskeletal abnormalities and enhance health-related functions, and lack of assessment of the effects of backpack weights on the balance factor in similar researches, the current study aimed to investigate the effects of carrying backpack on the static and dynamic balances of female students aged 9 to 11 years.

\section{MATERIALS AND METHODS}

Participants. The statistical sample consisted of 30 female students who were selected based on the available sample. With regards to the medical records and consultation of health teachers, all the students were confirmed to be healthy with no probable musculoskeletal problems that can prevent performance. For ethical treatment of the subjects, after notifying the parents and school administrators of the test method, superintendents of the school, volunteer students and their parents' written consents were obtained for the students' participation in the study.
Study Design. After the necessary arrangements with schools, the test method was described to the participants during a meeting. First, measurements of anthropometric characteristics, including height, weight, and leg length and body mass index were done.

$$
\text { Body mass index }=\frac{\text { Weight }(\mathrm{kg})}{\text { Height }(\mathrm{m} 2)}
$$

To start the dynamic balance test, the actual length of the leg from the anterior superior iliac spine to the internal malleolus was measured to normalize the data and compare the subjects. Also, the dominant leg was determined using shoot-the-ball test. To measure the leg length, the participants were first asked to lie on the bed on their backs. Then, the distance between the anterior superior iliac spine to the internal malleolus was measured for each subject, and each leg measurement was repeated twice and the results were averaged for use as the leg length (19). In addition, Y balance test was employed in this study. The participants stood in a single-leg stance at the centers of different directions to reach out with the other leg and then on their two legs normally, while remaining in this state for 10 to $15 \mathrm{~s}$ before the next attempt. All efforts were completed in one direction before taking another direction and were performed in a clockwise or counterclockwise sequential order (19). The subjects touched the farthest possible point with toes in each of the directions specified. The distance between the touch point and the center was a reaching distance, which was measured in $\mathrm{cm}$ (Figure 1). In order to obtain the difference between the average scores of the balance $(\mathrm{Y})$ test in each direction separately, the following formula was used:

$$
\text { Score }=\frac{\text { Reach distance }}{\text { Limb length }} \times 100
$$




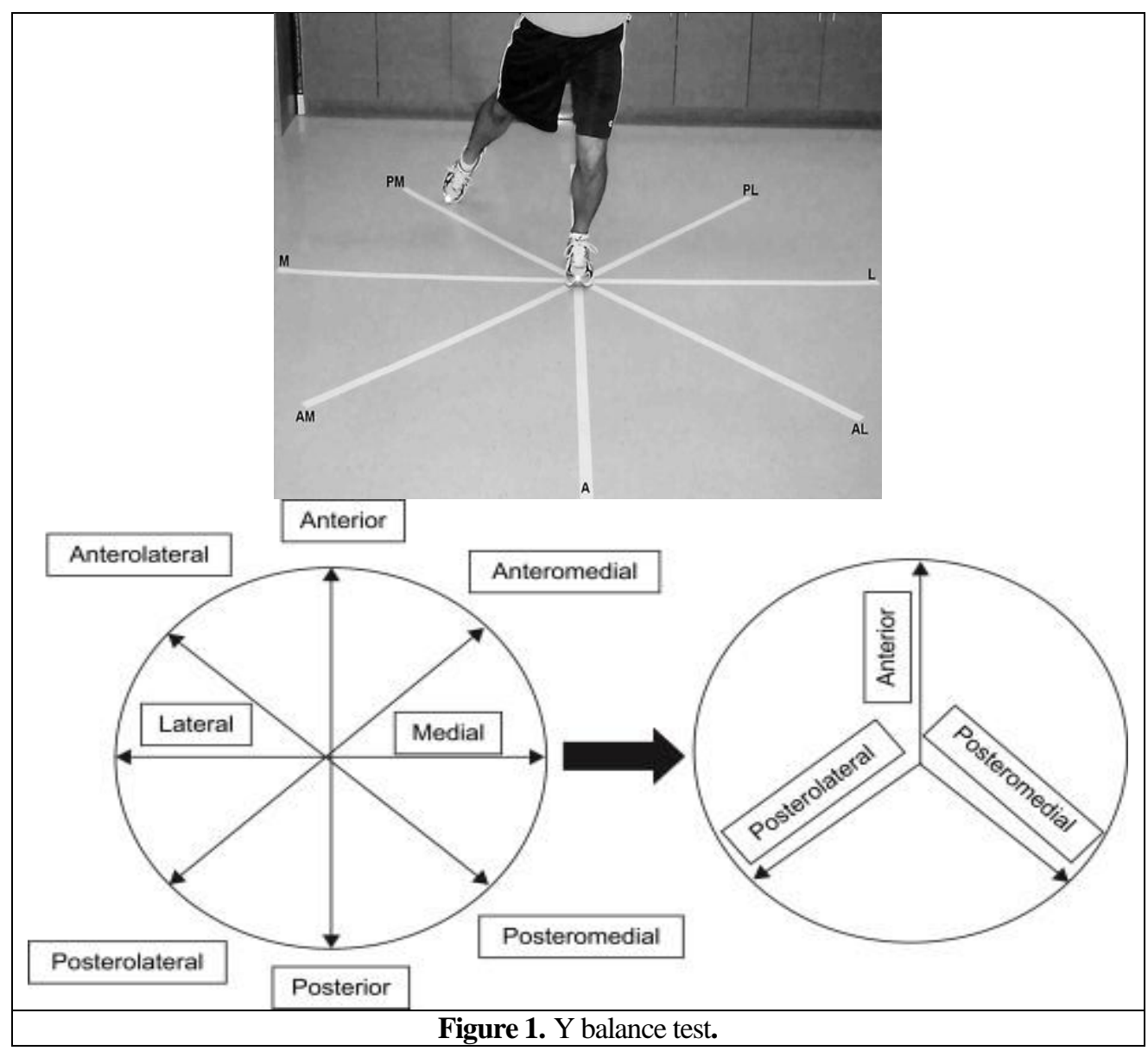

During the measurement phase of backpack weight, a digital scale with an accuracy of 2 decimal digits was used to measure the students' weights with their backpacks and all their properties and again without them. To reduce the errors in calculating the loads the students were carrying, the measurements were repeated on 3 even days of a week. The reason for the 3 measurements was that they would carry various properties and books on different days of the week. Then, the total weights of the students' backpacks with in the 3 days were averaged. After each subject underwent $\mathrm{Y}$ test without carrying a backpack, she was asked to carry a backpack of $10 \%$ of her body weight on her back. Meanwhile, the backpack placement on the back, rigidity and distance from the back or neck, hanging on one side, etc. were controlled. Moreover, to evaluate the static balance, a test of single-leg stance was conducted in a way that the subjects placed their hands on their thighs while standing on a flat surface without shoes and the non-supporting foot was located in front of the interior part of the supporting foot. Keeping this stance, the subject was asked to stand on her supporting leg front sole as long as possible. If the heel of the supporting leg touched the floor or the hands were separated from the thighs or the non-supporting foot sole was separated from the knee of the supporting leg, then the effort was ended. During the test, the subject looked at a sign in front of her face within a 4-m distance. Each subject underwent 3 trials, and the best time was recorded as her score.

Statistical Analysis. To sum up, the classification of raw scores and description of the sample sizes drawn from descriptive statistics (frequency, mean, percentage, 
standard deviation, graph and table) were employed. Furthermore, to analyze and infer the data, the statistical methods of paired t-test were used at a significance level of $\alpha<0.05$.

\section{RESULTS}

The demographic characteristics of the participants are summarized in table 1.

Table 1. Descriptive statistics relating to individual characteristics $(n=30)$.

\begin{tabular}{lccc}
\hline \multicolumn{1}{c}{ Index } & Mean & SD & p \\
\hline Weight $(\mathbf{k g})$ & 41.51 & 15.26 & 0.80 \\
\hline Height $(\mathbf{m})$ & 1.40 & 0.08 & 0.94 \\
\hline Leg length $(\mathbf{c m})$ & 73.76 & 5.4 & 0.81 \\
\hline BMI $\left(\mathbf{k g} / \mathbf{m}^{2}\right)$ & 20.68 & 5.4 & 0.64 \\
\hline
\end{tabular}

The static and dynamic balance scores of the participants are summarized in table 2 .

Given that the sample size is 30 persons, according to the central limit theorem for large samples (greater than 25 subjects), the distribution is asymptotically normal and there is no need to review it. Yet, using the Kolmogorov-Smirnov test, the present study was conducted. The null hypothesis of this test is that the desired variable follows a normal distribution. To compare the mean scores of static balance in both cases of carrying and not carrying a backpack, an independent t-test at a significance level of 0.05 was used, and the results are presented in Table 3.

Table 2. Descriptive statistics of dynamic balance scores in $\mathrm{cm}(\mathrm{n}=30)$

\begin{tabular}{lccc}
\hline & State & SD & Mean \\
\hline \multirow{2}{*}{ Left anterior } & Without backpack & 44.53 & 5.53 \\
& With backpack & 41.97 & 5.54 \\
\hline \multirow{2}{*}{ Right anterior } & Without backpack & 44.87 & 5.05 \\
& With backpack & 43.57 & 5.13 \\
\hline \multirow{2}{*}{ Left external posterior } & Without backpack & 41.36 & 6.01 \\
& With backpack & 4.10 & 5.25 \\
\hline \multirow{2}{*}{ Right external posterior } & Without backpack & 43.22 & 5.55 \\
& With backpack & 40.73 & 6.09 \\
\hline \multirow{2}{*}{ Left internal posterior } & Without backpack & 47.74 & 6.04 \\
& With backpack & 46.83 & 5.09 \\
\hline \multirow{2}{*}{ Right internal posterior } & Without backpack & 47.04 & 6.32 \\
& With backpack & 43.83 & 4.88 \\
\hline
\end{tabular}

Table 3. Comparison of the average static balance in the 2 cases of carrying and not carrying a backpack $(n=30)$

\begin{tabular}{ccccc}
\hline Variable & Mean \pm SD & df & t & p \\
\hline $\begin{array}{c}\text { Static balance with and without a } \\
\text { backpack }\end{array}$ & $1.05 \pm 2.62$ & 29 & 2.20 & $0.035^{*}$ \\
\hline & $*$ : significant at $\mathrm{p}<0.05$. & &
\end{tabular}

According to the above table, it is concluded that there is a significant difference between a single-leg stance of with and without a backpack $(\mathrm{p}=0.035)$.
Furthermore, according to the descriptive statistics, it was found that the test mean value was higher in the state of without as compared to with a backpack. 


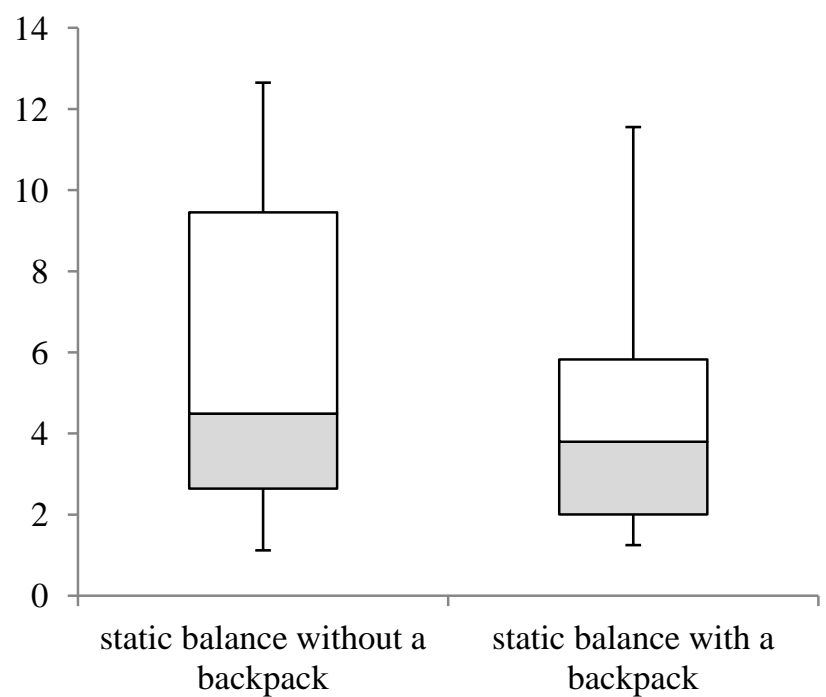

Diagram 1. Comparison of the average static balance in both case of carrying and not carrying a backpack.

Table 4 shows a significant relationship between the dynamic balance of with and without backpacks in the internal posterior (right foot), external posterior (right foot) and anterior (left foot) directions $(\mathrm{p}=0.003$,
0.006, and 0.003, respectively). However, no significant relationship was found between the dynamic balance with and without a backpack in other directions.

Table 4. Comparison of the average dynamic balance in both states of carrying and not carrying a backpack

\begin{tabular}{|c|c|c|c|c|}
\hline Variable & Mean \pm SD & df & $\mathbf{t}$ & $\mathbf{p}$ \\
\hline $\begin{array}{c}\text { Dynamic balance with and without a backpack } \\
\text { in the anterior direction (right foot) }\end{array}$ & $3.73 \pm 1.29$ & 29 & 1.90 & 0.067 \\
\hline $\begin{array}{c}\text { Dynamic balance with and without a backpack } \\
\text { in the anterior direction (left foot) }\end{array}$ & $2.62 \pm 2.56$ & 29 & 3.27 & 0.003 \\
\hline $\begin{array}{l}\text { Dynamic balance with and without a backpack } \\
\text { in the external posterior direction (right foot) }\end{array}$ & $4.63 \pm 2.48$ & 29 & 2.93 & 0.006 \\
\hline $\begin{array}{l}\text { Dynamic balance with and without a backpack } \\
\text { in the external posterior direction (left foot) }\end{array}$ & $4.08 \pm 0.94$ & 29 & 1.26 & 0.215 \\
\hline $\begin{array}{l}\text { Dynamic balance with and without a backpack } \\
\text { in the internal posterior direction (right foot) }\end{array}$ & $5.39 \pm 3.21$ & 29 & 3.26 & 0.003 \\
\hline $\begin{array}{l}\text { Dynamic balance with and without a backpack } \\
\text { in the internal posterior direction (left foot) }\end{array}$ & $5.00 \pm 0.91$ & 29 & 0.99 & 0.33 \\
\hline
\end{tabular}

\section{DISCUSSION AND CONCLUSION}

The aim of this research was to investigate the effect of backpack load on the static and dynamic balances of female students. The findings of the study indicate a reduction of static and in some directions, dynamic balances following the use of backpack with a weight of
$10 \%$ of body weight. Chansirinukor et al. (2001) stated that the weight of a backpack has a negative effect on the changes in the neck and shoulder states and that carrying a backpack of $15 \%$ of body weight for high school students aged 13-16 years, is too heavy to maintain natural body stance and upright position (20). 
Many researchers have reported that children aged 11-13 years adopt a bending forward body condition while carrying backpacks of $17 \%$ of their body weights. This implies that the mentioned backpack weight is too much for this age group. It can be interpreted thus: when carrying a load on the back, the trunk tendency to bend forward increases since the body center of gravity shifts to the back of the body (17) and thus the anterior trunk muscles react with a further enhancement in activities in an attempt to neutralize the displacement. Therefore, they play an effective role in making the upper body balance. This makes the dorsal muscles of the back to be involved and the anterior muscles to work harder $(21,22)$. All these changes in the body structure are referred to as compensatory reactions to stabilize the body's overall center of gravity (16). Whittfield, Legg, and Hedderley (2001) showed that carrying heavy bags imposes more physical pressure on students (5). It is said that school bags should not exceed $10 \%$ of a student's body weight. The appropriate amount of a student's backpack weight that enables him or her to carry it and maintain his or her normal upright physical condition is between 10and $17 \%$ of his or her body weight (20). The results of the current research which shows a reduction of balance in an individual's performance are consistent with those of Korovessis, Koureas, and Papazisis (2004), Fong, Hong, and Li (2004), Wesdock et al. (2002) and Chansirinukor et al. (2001), but not with those of Hung and Brugman (2000) and Wang et al. (2001) (20, 23-26). In their assessment of the effects of an external weight on postural stability of 22 female subjects (20.8 \pm 1.7 years), Heller et al. (2005) reported that there is a relationship between the load to be carried and stability. The standard measurements of postural stability demonstrated less stability in individuals carrying backpacks. Carrying an external load of $18.1 \mathrm{~kg}$, which is less than the minimum load carried by military personnel lowers the postural stability in healthy young women and may lead to the incidence of injuries such as ankle sprain in this population (27). By increasing teenagers' backpack weights, the amounts of trunk, head and neck bends are enhanced and since this change is a response to the imbalance, it will be inevitable. This would increase rectus spine muscle activity of the adolescents (4). Bloom and Woodhull-Mcneal (24) concluded that carrying a backpack of 19 and $14 \mathrm{~kg}$ of the body weight by men and women, respectively, would lead to their bending forward. When a backpack is heavy, the child bends his or her back excessively or his or her head and trunk forward to withstand the weight. The pressure on the neck and back muscles causes excessive fatigue and loss of balance and subsequent damage. If the weight of the bag is higher than a certain amount, the changes may be more than those allowed for teenagers due to their weakness and lack of strength in muscles and skeletons, thus leading to a change in the body structure or the occurrence of some disorders in balance and skeletomuscular problems (28). The use of backpacks with back slings which cause a major shift of mass to the pelvis reduces the pressure on the shoulders. Pelvis has a higher pressure endurance threshold than the shoulders, so it will help to increase public convenience. The sling also shifts the center of load to the back and lessens discomfort in the shoulders and neck $(19,29)$. Namazi Zadeh et al. (2003) reported that a rise in backpack weight as much as $10 \%$ or more of the body weight can reduce the length of steps (30). In addition, a weight of $10 \%$ increases the frequency of steps and angles of inclination of the trunk, head and neck forward. Backpacks with slings at the back and pelvis have been suggested in several studies since the slings help to keep the load close to the body and maintain a proper balance when walking $(4,22$, 27). The use of these slings have been recommended when carrying a load since they divide the load pressure, thus reducing the pressure just on one area and transferring the backpack weight from the back and shoulders to the hips and upper body (31). In an 
investigation, the researchers found a significant relationship between back pain and backpack weight and time of carrying it in all the age groups of students. An increase in backpack weight leads to an enhanced pressure on the spine in the sagittal plane. Bending of the body forward to create balance when carrying a heavy burden has ill effects on the natural curvatures in the back area. The heavyweights of backpacks lead to drooping shoulders and a hump in the body as well as an increase of curvature in the chest or upper back, thus resulting in students' shoulder, back and neck pains. Perhaps, reducing the students' additional properties by their parents contributes to alleviation of the amount of load, but the effects of management programs by the country's system of education to prevent the mentioned injuries are non-negligible. As a result of carrying backpacks, some disorders occur to the head, shoulder, spine and joints. These disorders can be caused by changes in neuromuscular control strategies and balance abnormalities leading to an increase in forces imposed on the joints and inter-joints, ligaments and muscle structures which cause an injury. Also, the defects in proprioception and joint position, loss of muscle strength, and impaired range of motion due to many reasons can cause imbalance, failure to maintain the center of gravity inside the supporting plane, occurrence of abnormal forces on the limbs and subsequently, injuries. Allocation of sufficient space and funding to public schools to provide suitable cabinets and shelves to avoid carrying extra loads to schools and back homes and adequate training of teachers on how to plan and control the properties students carry every day are evident. According to the results, it is recommended that the health officials of schools and parents should apply effective planning and training of students with regards to carrying of backpacks with appropriate weights.

\section{APPLICABLE REMARKS}

- An increase in a backpack weight will lead to enhanced pressure on the spine in the sagittal plane. Bending of the body forward for balancing when carrying a heavy load will have negative effects on the natural curvatures in the lumbar region.

- An increase in a backpack weight will lead to the enhanced flexions of the trunk, head and neck, which is unavoidable because of are action against the imbalance, thus raising teenagers' rectus spine muscle activities.

- Carrying heavier bags will impose more physical pressure on the students. The weight of school bags must not exceed $10 \%$ of the body weights of the students. A student's appropriate amount of backpack weight which he/she is able to carry and maintain his or her normal upright physical position should be between 10and $17 \%$ of the student's body weight.

\section{REFFRENCES}

1. Daneshmandi H, Hosseini SH, Mohammadi F. National Norm of backpack weight for Iranian male students. Sport Medicine Studies (Research on Sport Science). 2011;2(8):13-34 [Article in Farsi].

2. Devroey C, Jonkers I, De Becker A, Lenaerts G, Spaepen A. Evaluation of the effect of backpack load and position during standing and walking using biomechanical, physiological and subjective measures. Ergonomics. 2007;50(5):728-42.

3. Hoseini SH, Khuri A, Siavashi M, Amirian S, Abdolmohammadi A. Effect Of Carrying Backpacks With Different Weights On Electromyography Activity Of Rectus Abdominis And Lumbar Erector Spine Muscles In Eementary Schools Students. Olympic. 2012;20(3):73-83 [Article in Farsi].

4. Hosseini SH, Daneshmandi H, Rahmaninia F. The Comparison Of Physiological Effects Of Carrying Three Different Ergonomic Models Of School Bags In Students. Olympic. 2009;17(3):65-74 [Article in Farsi]. 
5. Whittfield J, Legg S, Hedderley D. The weight and use of schoolbags in New Zealand secondary schools. Ergonomics. 2001;44(9):819-24.

6. Forjuoh S, Schuchmann J, Lane B. Correlates of heavy backpack use by elementary school children. Public health. 2004;118(7):532-5.

7. Sadeghi H, Sarshin A, Hovanloo F. The Effect Of Whole Body Vibration Training On Dynamic Balance In Athletic Students. Journal Of Movement Science \& Sports. 2010;7(14):9-19 [Article in Farsi].

8. Smith B, Ashton KM, Bohl D, Clark RC, Metheny JB, Klassen S. Influence of carrying a backpack on pelvic tilt, rotation, and obliquity in female college students. Gait \& posture. 2006;23(3):263-7.

9. Chow DH, Kwok ML, Au-Yang AC, Holmes AD, Cheng JC, Yao FY, et al. The effect of load carriage on the gait of girls with adolescent idiopathic scoliosis and normal controls. Medical engineering \& physics. 2006;28(5):430-7.

10. Haywood K, Getchell N. Life span motor development: Human kinetics; 2009.

11. Filaire M, Vacheron J-J, Vanneuville G, Poumarat G, Garcier J-M, Harouna Y, et al. Influence of the mode of load carriage on the static posture of the pelvic girdle and the thoracic and lumbar spine in vivo. Surgical and radiologic Anatomy. 2001;23(1):27-31.

12. Singh T, Koh M. Effects of backpack load position on spatiotemporal parameters and trunk forward lean. Gait \& posture. 2009;29(1):49-53.

13. Grimmer K, Dansie B, Milanese S, Pirunsan U, Trott P. Adolescent standing postural response to backpack loads: a randomised controlled experimental study. BMC Musculoskeletal Disorders. 2002;3(1):10.

14. Singh T, Koh M. Lower limb dynamics change for children while walking with backpack loads to modulate shock transmission to the head. Journal of biomechanics. 2009;42(6):736-42.

15. Nouri J, Azadeh A, Mohammad Fam I. The evaluation of safety behaviors in a gas treatment company in Iran. Journal of Loss Prevention in the Process Industries. 2008;21(3):319-25.

16. Hong Y, cheung, c.k. Electromyography response of back muscles during load carriage. Gait\& posture. 2003;17(1):28-33.

17. Negrini S, Carabalona R, Sibilla P. Backpack as a daily load for schoolchildren. The Lancet. 1999;354(9194):1974.

18. Brackley HM, Stevenson JM. Are children's backpack weight limits enough?: A critical review of the relevant literature. Spine. 2004;29(19):2184-90.

19. Dehnavi H, Khorramnezhad H, Hassanpanah H, Hajibigloo M. The Effect of Fatigue on Functional Stability in the Basketball Players with Functional Ankle Instability. American Journal of Sports Science. 2013;1(3):28-32.

20. Chansirinukor W, Wilson D, Grimmer K, Dansie B. Effects of backpacks on students: measurement of cervical and shoulder posture. Australian Journal of physiotherapy. 2001;47(2):110-6.

21. Hong Y, Li J-X, Fong DT-P. Effect of prolonged walking with backpack loads on trunk muscle activity and fatigue in children. Journal of Electromyography and Kinesiology. 2008;18(6):990-6.

22. Reneman M, Poels B, Geertzen J, Dijkstra P. Back pain and backpacks in children: Biomedical or biopsychosocial model? Disability \& Rehabilitation. 2006;28(20):1293-7.

23. Fong DTP, Hong Y, Li J, editors. The Effect of Load Carriage and Schoolbag Design on Lateral Trunk Posture during Stairs Descent in Children. 22 International Symposium on Biomechanics in Sports; 2004; Ottawa, Canada: International Society of Biomechanics in Sports.

24. Korovessis P, Koureas G, Papazisis Z. Correlation between backpack weight and way of carrying, sagittal and frontal spinal curvatures, athletic activity, and dorsal and low back pain in schoolchildren and adolescents. Journal of spinal disorders \& techniques. 2004;17(1):33-40.

25. Pascoe DD, Pascoe DE, Wang YT, Shim DM, Kim CK. Influence of carrying book bags on gait cycle and posture of youths. Ergonomics. 1997;40(6):631-41.

26. Wesdock K, Henley J, Masiello G, Nogi J. The Effects of Backpack Use on Posture and Gait in School-Age Children - A Pilot Study 2002 [cited 2015]. Available from: http://biomotionlabs.com/wpcontent/uploads/2011/08/Effects-of-Backpack-Use-on-Posture-Gait-in-School-Age-Children.pdf.

27. Abuzayan K, Alabed H, Ali S. The Effects of Adding External Mass and Localised Fatigue upon Static and Dynamic Balance. Ergonomics. 2010;3(15):55-96.

28. Delahunt E. Neuromuscular contributions to functional instability of the ankle joint. Journal of Bodywork and Movement Therapies. 2007;11(3):203-13.

29. Mackie HW, Stevenson JM, Reid SA, Legg SJ. The effect of simulated school load carriage configurations on shoulder strap tension forces and shoulder interface pressure. Applied ergonomics. 2005;36(2):199-206.

30. Namazi Zadeh M, Ebrahim K, Sarreshteh M, Salehi H. Kinematics Effects Of Carrying The School Backpack On Gait Pattern And Posture Of Youngsters. Harakat. 2003(16):5-24 [Article in Farsi].

31. Al-Khabbaz YS, Shimada T, Hasegawa M. The effect of backpack heaviness on trunk-lower extremity muscle activities and trunk posture. Gait \& posture. 2008;28(2):297-302.

Bahiraei, S., Jafarian, M., MohammadAliNasab, E. (2015). Ann Appl Sport Sci, 3(3): 57-66. 
تازههاى علوم كاربردى ورزش

مقاله اصيل

دوره سوم، شماره سوم

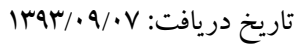

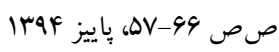

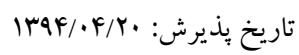

\section{بررسى اثر وزن كولهيشتى بر تعادل ايستا و يوياى دانش آموزان دختر}

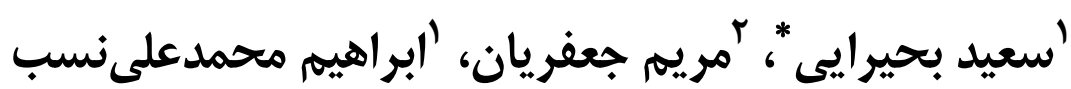

1. دانشجوى دكترى آسيبشناسى ورزشى و حركات اصلاحى، دانشكده علوم ورزشى، دانشخاه كيلان، رشت، ايران. ז. كارشناس ارشد آسيبشناسى ورزشى و حركات اصلاحى، دانشكده علوم ورزشى، دانشخاه گيلان، رشت، ايران.

جكيده

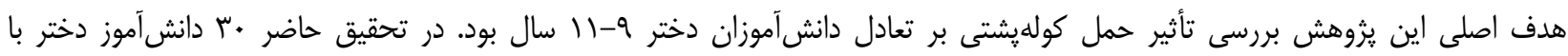

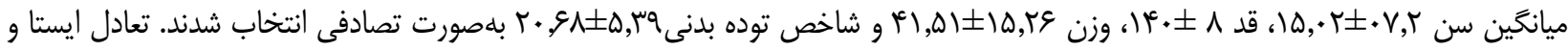

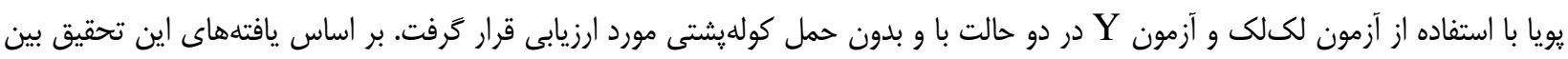

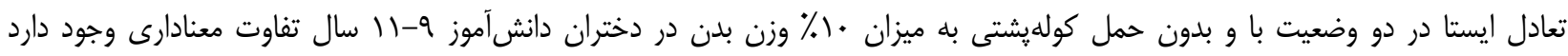

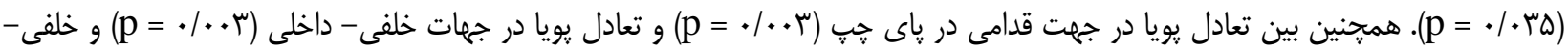

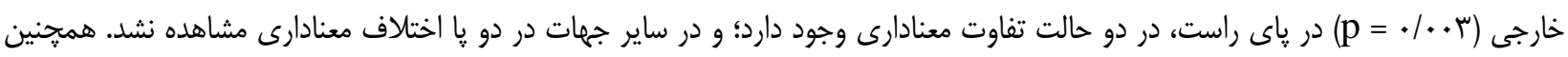

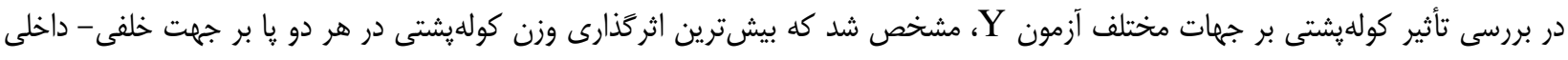

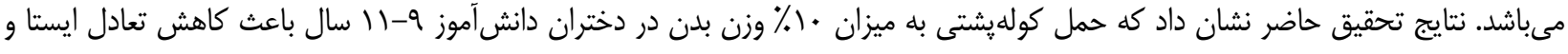

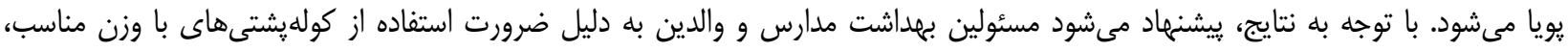

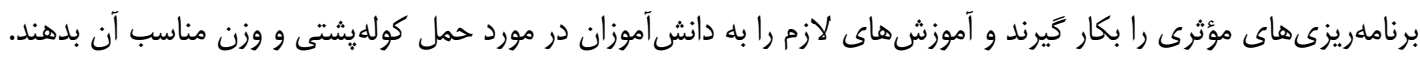

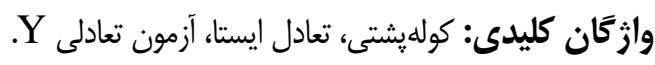

